\title{
And how shall we deal with adaptation and implementation of NICE schizophrenia guidelines in Italy?
}

\author{
Much more than just cutting a good figure ${ }^{l}$
}

\author{
GIUSEPPE CARRÀ, ${ }^{1}$ GIOVANNI SEGAGNI LUSIGNANI, ${ }^{2}$ PAOLA SCIARINI, ${ }^{2}$ \\ FRANCESCO BARALE, ${ }^{2}$ ALESSANDRA MARINONI, ${ }^{2}$ MASSIMO CLERICI ${ }^{3}$
}

\author{
${ }^{1}$ Department of Mental Health Sciences, Royal Free and University College Medical School, London (United Kingdom) \\ ${ }^{2}$ Department of Health Sciences, Section of Medical Statistics and Epidemiology, University of Pavia, Pavia (Italy) \\ ${ }^{3}$ Department of Neurosciences and Biomedical Technologies, University of Milan Bicocca Medical School, Milano (Italy)
}

\section{BACKGROUND}

During the 1990s Evidence-Based Medicine emphasized the need to promote evidence-based practice, leading to a rise of practice guidelines throughout medicine (Audet et al., 1990; Lomas, 1991), and expanding the systematic use of scientific evidence in clinical decisionmaking (Guyatt \& Rennie, 2002). Though administrators, clinicians, advocates and researchers generally agree that they should provide the most effective mental health treatments, implementing evidence-based practices in standard settings is not straightforward (Drake et al., 2003). Indeed, there is some evidence to suggest that organisational culture may be a relevant factor in health care performance, still articulating the nature of that relationship proves tricky. Current policy prescriptions, which seek service improvements through organisational transformation, are in need of a more secure evidential base (Scott et al., 2003).

Evidence-Based Medicine currently enjoys a good reputation in Italy (Ballini \& Liberati, 2004), but the complexity and potential utility of information now avail-

\footnotetext{
Address for correspondence: Dr. P. Sciarini, Department of Health Sciences, Section of Medical Statistics and Epidemiology, University of Pavia, Via Bassi 21, 27100 Pavia. Fax: +39-0382-987570

E-mail: paola.sciarini@unipv.it Declaration of Interest: None.

'Beppe Severgnini. La Bella Figura: A Field Guide to the Italian Mind. New York: Broadway Books, 2006.
}

able for guiding policy and practice decisions make vital methods for synthesis, adaptation and implementation of research information (Anderson et al., 2005). However, simply publishing and distributing clinical guidelines formulated to help to translate the scientific evidence literature into concise statements (Rogers, 1995) - is not enough to change the practice of clinicians (Cabana et al., 1999). The mental health field is no exception (Hickie \& Blashki, 2006) - practice guidelines being perceived as externally imposed and cost-containment tools rather than as decision-supporting tools (Grilli et al., 1996; Formoso et al., 2001).

The NICE-Schizophrenia Guidelines (SG) (National Collaborating Centre For Mental Health, 2003) were translated into Italian at a significant time as concerns upcoming review of National mental health care models (Carrà et al., 2004). NHS mental health services in England and in Italy, share indeed principles - e.g. providing a universal and comprehensive service with equal access for all, free at the point of use, based on clinical need, not ability to pay - but also weaknesses such as difficulties in translating the best research evidence available to implementable clinical practice recommendations (Carrà et al., 2004; Kendall et al., 2004; 2005). In a word, translating good guidelines does not ensure their use in practice in Italian mental health services. Therefore, to maximise the likelihood of NICE-SG being used we need somewhat coherent dissemination and implementation strategies to capitalise on known positive factors and to deal with obstacles to implementation that have to be identified (Feder et al., 1999; Grol et al., 2005). 


\section{BARRIERS AND FACILITATORS FOR NICE-SG IN ITALY}

A number of frameworks have been proposed in the literature for organising and making decisions about which high quality guidelines to adopt (e.g. Graham et al., 2003; Hysong et al., 2007). However, common requirements for identifying, critically appraising, and adopting or adapting guidelines for local use include an assessment of their credibility, utility and measurability (Feder et al., 1999). Appraising the credibility in terms of validity of existing guidelines concerns the methodological rigour in development procedures. In a recent methodological comparison using a validated guidelines appraisal instrument - the Appraisal Guideline Research and Evaluation Europe - (AGREE Collaboration, 2003), the NICE-SG had the highest methodological quality according to AGREE and the highest scores in five out of six domains (Gaebel et al., 2005). Guidelines utility is related to:

a) the assessment of the determination of the aggregate evidence quality in support of a proposed recommendation;

b) the evaluation of the anticipated balance between benefits and harms when the recommendation is carried out; and

c) the designation of recommendation strength (American Academy of Pediatrics Steering Committee on Quality Improvement and Management, 2004).

Identifying local needs, surveying discrepancies between current and evidence-based practices, and detecting cost-effective recommendations are all preliminary steps to assess guidelines utility (Glanville et al., 1998; Schunemann et al., 2003). NICE-SG content analysis was found including numerous key recommendations with respect to a wide range of psychopharmacological, psychological and psychosocial interventions. It would be really unlikely to be unable to locate an appropriate recommendation, addressing Italian local healthcare setting flaws (Carrà et al., 2007). Nevertheless, it remains unresolved how a core set of valid psychiatric care recommendations can be defined which could easily be used to develop national or regional schizophrenia guidelines without disregarding local health systems or cultures (Gaebel et al., 2005). The usefulness of specific service delivery systems such as Assertive Community Treatment, Crisis Resolution and Home Treatment, and Early Intervention Services, could be disputed in European countries like Italy with well-developed community care systems where an alternative model based on close integration of a full range of types of care is in place (Johnson, 2008). Furthermore, several NICE-SG recommendations (e.g. those for family interventions and Cognitive-behavioural therapy) would require expensive education and training of health care professionals, limiting their cost-effective value. Finally, adopting the guidelines involves reformatting the recommendations in terms of measurable criteria, within planned audits. As with all audits, the stakeholders should agree the criteria, standards, exceptions and definition of terms. Once the audit is complete, the stakeholders should review the findings of measurement, identify if practice can be improved and agree on a plan to achieve any desired improvements, repeating the measurement of actual practice to confirm that those improvements are being achieved. A few attempts to convert NICE-SG recommendations into quantitative outputs have been carried out in England locally (e.g. Ozbilen \& Cottrell, 2007), nationwide (Commission for Healthcare Audit and Inspection, 2007), and also abroad (Ruggeri, 2008). However, given the complexity of a number of NICE-SG recommendations, it would be extremely useful providing Mental Health Care Trusts with a defined set of audit tools and criteria, as developed for example for Dementia (National Institute for Clinical Excellence, 2006), though a limited amount of local key priorities criteria could encourage the staff discussion of clinical audit findings and, where recommendations are not being met, the development of an action plan.

\section{ADAPTATION AND IMPLEMENTATION STRATEGIES FOR NICE-SG WITHIN ITALIAN MENTAL HEALTH SERVICES}

Establishing which recommendations are worth to be adopted is deeply linked to a preliminary assessment of the local routine daily practice (Grol \& Grimshaw, 2003). Furthermore, assessing the likely impact of chosen recommendations must include the identification of broader elements affecting the outcome of a number of evidencebased treatments. For example, supported employment programmes heavily rely on local welfare systems in terms of available financial benefits and service provision, but are also strictly connected to local stakeholders' fiscal boosts and policies against discrimination by employers (Bond \& Drake, 2008).

Once authorities, trusts, primary care groups, or individual general practices have acknowledged guidelines of suitable quality, these need to be adapted for use within the local healthcare setting (Feder et al., 1999). 
Nevertheless, change is rarely as easy if the improvement requires multifaceted transformations in clinical practice or in the organisation of care, and local adaptation groups may want to change also recommendations based on good evidence, though the reasons for this should be overtly addressed (Grol \& Grimshaw, 2003). A number of attributes of clinical guidelines might positively influence whether they are used in clinical practice: topic related to acute health problems; better quality of supporting evidence; compatibility of the recommendation with existing principles; less complexity of the decisionmaking needed; more concrete description of the desired performance; and fewer new skills and organisational transformation needed (Grilli \& Lomas, 1994; Grol et al., 1998; Foy et al., 2002; Burgers et al., 2003). The mental health field is actually no exception (e.g. Drake et al., 1996; Jerrel \& Ridgely, 1999) and these criteria should be carefully considered choosing recommendations to be implemented in Italian Mental Health Trusts. Furthermore, identifying relevant stakeholders for the guidelines development group, means identifying all the groups whose activities would be covered by the guidelines or who have other legitimate reasons for having an input into the process. This is important to ensure adequate discussion of the evidence, though it may be necessary to trade off full representation against the requirement of having a functional group (Shekelle et al., 1999). How much users' and carers' views could be taken into account when adapting the recommendations for Italian Mental Health Care Trusts is questionable because of the relatively poor National tradition of such associations.

A multifaceted dissemination and implementation strategy (Moulding et al., 1999) is much more likely to increase the probability of uptake in practice of NICESG. However, passive dissemination (for example, to be honest, translating and publishing high quality guidelines) is generally ineffective and is unlikely to result in behavioural change when used alone (Grimshaw et al., 2004). Better-tailored programmes and strategies aimed at specific performance changes are probably needed, such as implementation with performance review and feedback (Winkens et al., 1996), and interactive education in small groups of peers (Smeele et al., 1999). Indeed, outreach visits are found to be very useful along with financial reimbursement for the extra work involved in using the guidelines (Grol, 2001) for changing professional behaviour. The Italian Society of Psychiatric Epidemiology (Società Italiana di Epidemiologia Psichiatrica, SIEP) has promoted a Project - the SIEPDIRECT'S (DIscrepancy between Routine practice and Evidence in psychiatric Community Treatments on
Schizophrenia) (Ruggeri, 2008; Semisa et al., 2008; Ruggeri et al., 2008) Project - that is actually the best available example of complex dissemination intervention for NICE-SG in Italy so far, with group interactive, educational sessions, local consensus, and opinion leaders support (Ruggeri, 2008). However, changes in clinical practice are only partly within doctors' control; the prevailing professional and organisational culture towards quality determines the outcome to a large extent (De Maeseneer et al., 2003). The size, the complexity and the attitude of an organisation to adapting to frequent change will affect the feasibility of implementation strategies (Grol \& Grimshaw, 2003). The presence of organisational barriers may require specific interventions and considerable financial resources. To what extent environmental support is available from policy-makers to encouraging and maintaining NICE-SG adoption in Italy is unclear, despite recent improvements in clinical governance systems (Fattore \& Jommi, 1998; Fattore, 1999). An organisational culture that is supportive, encourages flexibility, and rewards attitude to change is still under development in Italian Mental Health Trusts. Their policies have often been criticised as too arbitrary, monocratic, and given over to economic considerations, regardless any measurable merit in staff performances (Carpenter, 2004).

\section{CONCLUSIONS}

So how did we deal with adaptation and implementation of NICE-SG in Italy?

We all have to thank SIEP for its brave and valuable National project (Semisa et al., 2008); SIEP Board members' hard work was indeed much more than just "cutting a good figure". However, guidelines are not self-implementing and must be contextualized to the concrete care practices (Torrey et al., 2001). Ideally, all motivated Italian Mental Health Care Trusts should establish a well designed, well prepared, and preferably pilot tested before use, programme to implement chosen recommendations from NICE-SG. Such a programme should be made into the normal channels and structures for really improving quality of care (Grol, 2001). Sustained change actually requires a restructuring of the course of the day by day work so that regular procedures make it accepted for the clinician to provide care in the new mode (Batalden \& Stoltz, 1993). To sustain evidence-based practice over time, ongoing funding is vital. Clinicians, also in the mental health field, are generally not eager to change and must be convinced to adopt a new practice, for sure not in terms of extra working hours, but realisti- 
cally via administrative rules and financial incentives. Obviously, practice implementation can easily fail. So, to succeed, the implementation programme must have adequate resources and the efforts of stakeholders must be allied to support the new practices (Torrey et al., 2001). Hopefully, Italian policy makers and administrators will remember the quote, whose cultural influence should still be a mainstay in Italian social life, sine pecunia non cantantur missae, perhaps freely translated as competencies and financial resources are the bread and butter of change.

\section{REFERENCES}

AGREE Collaboration (2003). Development and validation of an international appraisal instrument for assessing the quality of clinical practice guidelines: the AGREE project. Quality and Safety in Health Care 12, 18-23.

American Academy of Pediatrics Steering Committee on Quality Improvement and Management (2004). Classifying recommendations for clinical practice guidelines. Pediatrics 114, 874-877.

Anderson L.M., Brownson R.C., Fullilove M.T., Teutsch S.M., Novick L.F., Fielding J. \& Land G.H. (2005). Evidence-based public health policy and practice: promises and limits. American Journal of Preventive Medicine 28, Suppl. 5, 226-230.

Audet A.M., Greenfield S. \& Field M. (1990). Medical practice guidelines: current activities and future directions. Annals of Internal Medicine 113, 709-714.

Ballini L. \& Liberati A. (2004). Linee-guida per la Pratica Clinica. Metodologia per l'Implementazione. Il Pensiero Scientifico Editore: Roma.

Batalden P.B. \& Stoltz P.K. (1993). A framework for the continual improvement of health care: building and applying professional and improvement knowledge to test changes in daily work. Joint Commission Journal on Quality Improvement 19, 424-445.

Bond G.R. \& Drake R.E. (2008). Predictors of competitive employment among patients with schizophrenia. Current Opinion in Psychiatry 21, 362-369.

Burgers J., Grol R., Zaat J., Spies T., Van der Bij A. \& Mokkink H. (2003). Characterics of effective clinical guidelines for general practice. British Journal of General Practice 53, 15-19.

Cabana M.D., Rand C.S., Powe N.R., Wu A.W., Wilson M.H., Abboud P.A. \& Rubin H.R. (1999). Why don't physicians follow clinical practice guidelines? A framework for improvement. Journal of the American Medical Association 282, 1458-1465.

Carpenter G. (2004). Italian health bill to overhaul management of NHS hospitals. Bill will phase out monocratic "supermanagers" and give greater powers to hospital doctors. Lancet 363, 138.

Carrà G., Barale F. \& Marinoni A. (2004). Presentazione dell'edizione italiana. In National Collaborating Centre for Mental Health. Schizofrenia. Linee Guida Cliniche Complete per gli Interventi Fondamentali nella Medicina di Base e Specialistica (ed. G. Carrà, F. Barale e A. Marinoni). Il Pensiero Scientifico Editore: Roma.

Carrà G., Segagni G., Sciarini P. \& Marinoni A. (2007). Adaptation and implementation strategies for NICE schizophrenia guidelines in Italy. Rivista di Psichiatria 42, 49-58.

Commission for Healthcare Audit and Inspection (2007). No voice, no choice. A joint review of adult community mental health services in Retrieved September 17, 2008, from http://www.healthcarecommissio. org.uk/_db/_documents/Communicty_mental_health_-_full_report.pdf

De Maeseneer J.M., van Driel M.L., Green L.A. \& van Weel C. (2003). The need for research in primary care. Lancet 362, 1314-1319.
Drake R.E., McHugo G.J., Becker D.R., Anthony W.A. \& Clark R.E. (1996). The New Hampshire study of supported employment for people with severe mental illness. Journal of Consulting and Clinical Psychology 64, 391-399.

Drake R.E., Torrey W.C. \& McHugo G.J. (2003). Strategies for implementing evidence-based practices in routine mental health settings. Evidence-Based Mental Health 6, 6-7.

Fattore G. (1999). Clarifying the scope of Italian NHS coverage. Is it feasible? Is it desirable? Health Policy 50, 123-142.

Fattore G. \& Jommi C. (1998). The new pharmaceutical policy in Italy. Health Policy 46, 21-41.

Feder G., Eccles M., Grol R., Griffiths C. \& Grimshaw J. (1999). Clinical guidelines: using clinical guidelines. British Medical Journal 318, 728-730.

Formoso G., Liberati A. \& Magrini N. (2001). Practice guidelines: useful and "participative" method? Survey of Italian physicians by professional setting. Archives of Internal Medicine 161, 2037-2042.

Foy R., MacLennan G., Grimshaw J., Penney G., Campbell M. \& Grol R. (2002). Attributes of clinical recommendations that influence change in practice following audit and feedback. Journal of Clinical Epidemiology 55, 717-722.

Gaebel W., Weinmann S., Sartorius N., Rutz W. \& McIntyre J.S. (2005). Schizophrenia practice guidelines: international survey and comparison. British Journal of Psychiatry 187, 248-255.

Glanville J., Haines M. \& Auston I. (1998). Finding information on clinical effectiveness. British Medical Journal 317, 200-203.

Graham D.I., Harrison M.B. \& Brouwers M. (2003). Evaluating and adapting practice guidelines for local use: a conceptual framework. In Clinical Governance in Practice (ed. S. Pickering and J. Thompson), pp. 213-229. Harcourt: London.

Grilli R. \& Lomas J. (1994). Evaluating the message: the relationship between compliance rate and the subject of a practice guideline. Medical Care 32, 202-213.

Grilli R., Penna A., Zola P. \& Liberati A. (1996). Physicians' view of practice guidelines. A survey of Italian physicians. Social Science \& Medicine 43, 1283-1287.

Grimshaw J.M., Thomas R.E., MacLennan G., Fraser C., Ramsay C.R., Vale L., Whitty P., Eccles M.P., Matowe L., Shirran L., Wensing M., Dijkstra R. \& Donaldson C. (2004). Effectiveness and efficiency of guideline dissemination and implementation strategies. Health Technology Assessment 8(6), iii-iv, 1-72.

Grol R. (2001). Successes and failures in the implementation of evidence-based guidelines for clinical practice. Medical Care 39, Suppl. 2, 46-54.

Grol R. \& Grimshaw J. (2003). From best evidence to best practice: effective implementation of change in patients' care. Lancet 362, 1225-1230.

Grol R., Dalhuijsen J., Thomas S., Veld C., Rutten G. \& Mokkink H. (1998). Attributes of clinical guidelines that influence use of guidelines in general practice: observational study. British Medical Journal 317, 858-861.

Grol, R., Wensing M. \& Eccles M. (2005). Improving Patient Care: The Implementation of Change in Clinical Practice. Elsevier: Edinburgh.

Guyatt G. \& Rennie D. (Eds) (2002). Users' Guides to the Medical Literature. American Medical Association: Chicago.

Hickie I.B. \& Blashki G.A. (2006). Evidence into practice: the mental health hurdle is high. Medical Journal of Australia 184, 542-543.

Hysong S.J., Best R.G. \& Pugh J.A. (2007). Clinical practice guideline implementation strategy patterns in veterans affairs primary care clinics. Health Services Research 42, 84-103.

Jerrel J.M. \& Ridgely M.S. (1999). Impact of robustness of program implementation on outcomes of clients in dual diagnosis programs. Psychiatric Services 50, 109-112.

Johnson S. (2008). So what shall we do about assertive community treatment? Epidemiologia e Psichiatria Sociale 17, 110-114.

Kendall T., Pilling S., Pettinari C. \& Whittington C. (2004). Clinical Guidelines in Mental Health I: The National Collaborating Centre for Mental Health. Psychiatric Bulletin 28, 156-159. 
Kendall T., Pilling S., Whittington C., Pettinari C. \& Burbeck R. (2005). Clinical Guidelines in Mental Health II: a guide to making NICE Guidelines. Psychiatric Bulletin 29, 3-8.

Lomas J. (1991). Words without action? The production, dissemination, and impact of consensus recommendations. Annual Review of Public Health 12, 41-65.

Moulding N.T., Silagy C.A. \& Weller D.P. (1999). A framework for effective management of change in clinical practice: dissemination and implementation of clinical practice guidelines. Quality in Health Care 8, 177-183.

National Collaborating Centre For Mental Health (2003). Schizophrenia: Full National Clinical Guideline on Core Interventions in Primary and Secondary Care. Gaskell \& the British Psychological Society: London.

National Institute for Clinical Excellence (NICE) (2006). Audit Criteria for NICE Clinical Guideline No. 42 Dementia: Supporting People with Dementia and Their Careers in Health and Social Care. NICE.

Ozbilen M. \& Cottrell D. (2007). Compliance with NICE guidance: concurrent use of different antipsychotic drugs. Clinical Governance: An International Journal 12, 118-121.

Rogers E.M. (1995). The challenge: lessons for guidelines from the diffusion of innovations. Journal on Quality Improvement 21, 324-328.

Ruggeri M. (2008). Guidelines for treating mental illness: love them, hate them. Can the SIEP-DIRECT'S Project serve in the search for a happy medium? Epidemiologia e Psichiatria Sociale 17(4), 270-277.

Ruggeri M., Lora A. \& Semisa D. on behalf of the SIEP-DIRECT'S Group (2008). The SIEP-DIRECT'S Project on the discrepancy between routine practice and evidence. An outline of the main findings and the practical implications for the future of community based mental health services. Epidemiologia e Psichiatria Sociale 17(4), 358-368.

Schunemann H.J., Best D., Vist G. \& Oxman A.D., GRADE Working Group (2003). Letters, numbers, symbols and words: how to communicate grades of evidence and recommendations. Canadian Medical Association Journal 169, 677-680.

Scott T., Mannion R., Marshall M. \& Davies H. (2003). Does organisational culture influence health care performance? A review of the evidence. Journal of Health Services Research Policy 8, 105-117.

Semisa D., Lora A., Morosini P. \& Ruggeri M. (2008). The SIEPDIRECT'S Project on the discrepancy between routine practice and evidence in the treatment of schizophrenia. The design, the indicators, and the methodology of the study (in Italian). Epidemiologia e Psichiatria Sociale 17(4), 278-290.

Shekelle P.G., Woolf S.H., Eccles M. \& Grimshaw J. (1999). Clinical guidelines: developing guidelines. British Medical Journal 318, 593-596.

Smeele I., Grol R., Van Schayck C., van den Bosch W.J., van den Hoogen H.J. \& Muris J.W. (1999). Can small group education and peer review improve care for patients with asthma/chronic obstructive pulmonary disease? Quality in Health Care 8, 92-98.

Torrey W.C., Drake R.E., Dixon L., Burns B.J., Flynn L., Rush A.J., Clark R.E. \& Klatzker D. (2001). Implementing evidence-based practices for persons with severe mental illnesses. Psychiatric Services 52, 45-50.

Winkens R., Pop P., Grol R., Bugter-Maessen A., Kester A., Beusmans G. \& Knottnerus J.A. (1996). Effects of routine individual feedback over nine years on general practitioners' requests for tests. British Medical Journal 312, 490. 